[2] Ünal E, Arin G, Karaca Nb, Kiraz S, Akdoğan A, Kalyoncu U, et al. Romatizmalı hastalar için bir yaşam kalitesi ölçeğinin geliştirilmesi: madde havuzunun oluşturulması. Journal of Exercise Therapy and Rehabilitation. 2017;4(2):67-75

[3] Kisacik P, Unal E, Akman U, Yapali G, Karabulut E, Akdogan A. Investigating the effects of a multidimensional exercise program on symptoms and antiinflammatory status in female patients with ankylosing spondylitis. Complementary therapies in clinical practice. 2016;22:38-43.

Disclosure of Interests: None declared

DOI: 10.1136/annrheumdis-2019-eular.7955

\section{FRI0714-HPR A PILOT NURSE-LED TELEPHONE TRIAGE LINE OF PATIENTS WITH RHEUMATOLOGIC RARE DISEASES IN A TERTIARY CENTER}

Eva Kis $^{1,2}$, Gabriela Ciursa ${ }^{1}$, Bianca Jurjiu ${ }^{1}$, lleana Filipescu ${ }^{1}$, Laura Muntean ${ }^{1}$, Siao-Pin Simon ${ }^{1}$, Simona Rednic ${ }^{1}$, Laura Damian ${ }^{1}$. ${ }^{1}$ Emergency Clinical County Hospital Cluj, Rheumatology, Cluj-Napoca, Romania; ${ }^{2}$ Emergency Clinical County Hospital Cluj, Quality Insurance, Cluj-Napoca, Romania

Background: The general rheumatology outpatient clinics are facing an increasing workload. The patients already in evidence with rare or complex inflammatory diseases, such as inflammatory myopathies, systemic lupus erythematosus, mixed connective tissue diseases, systemic sclerosis, Sjogren's syndrome, relapsing polychondritis, systemic vasculitides and other collagen-vascular diseases are being scheduled for outpatient or hospital assessment at the current visit. However the patients may need earlier appointments, given the possibility of flares or other issues. Objectives: To assess the role of a nurse-led telephonic triage line in patients with rare rheumatologic diseases.

Methods: The nurses accepting to be enrolled in the programme answered the phone for the patients already in the department's and their follow-up with rare or complex inflammatory rheumatic diseases. A 2-hours training programme with attending physicians was completed. Respecting confidentiality agreement regulations, the calls were registered with the nume, diagnosis and phone number on a standard form. The calls reasons were recorded: appointments scheduling, medical issues or others. The alarming symptomes and signs requiring doctor advice or earlier appointments were checked on a short form: aggravating dyspnea, dysphagia, weakness or Raynaud's phenomenon, ulcerations, etc. Other issues, such as lumbar pain, joint pain, nausea, heartburn, etc requiring counselling, were registered as well.

Results: Over 2 months, 280 calls from patients with rare rheumatologic diseases were received, out of which 171 (61\%) were for scheduling or changing appointments. The rest were for medical advice regarding minor ailments, medication side effects, regular blood tests or other investigations performed after the last visit, issues regarding travelling etc. The triage nurses referred the patients to Emergency in 2 cases $(0.7 \%)$, to the General Practitioner in 28 cases (10\%) or planned an early appointment to the attending rheumatologist for medical issues in 20 cases (7.3\%), briefed the attending physician in 94 cases (33\%) and offered counselling in the other cases (49\%), which included: medication side effects, analyses to be repeated, diet and promoting self-care.

Conclusion: Telephonic calls, managed by experienced nurses, documented by standardized forms, are valuable additional tools in the management of rare inflammatory diseases. The pilot phone triage procedure improve patient's access to healthcare services. Periodic specialty training regarding rheumatologic emergency and communication skills increase the quality of this approach in rare diseases.

\section{REFERENCES:}

[1] Thwaites C, Ryan S, Hassel A, Rheumatology (Oxford) 2008; 47(4):522-5, Doi: 10.1093/rheumatology/ken041

[2] Fereira RO, Marques A, Cruz Mendes AMO, da Silva JA, Acta Reumatol Portuguesa 2015; 40:163-8.

Disclosure of Interests: None declared DOI: 10.1136/annrheumdis-2019-eular.7942

\section{FRI0715-HPR FACTORS WHICH IMPACT COMPLETION AND NON- COMPLETION OF PHYSICAL ACTIVITY INTERVENTIONS FOR PEOPLE WITH RHEUMATOID ARTHRITIS: A SYSTEMATIC REVIEW}

Louise Larkin. University of Limerick, Limerick, Ireland

Background: Rheumatoid arthritis (RA) is a systemic inflammatory condition which results in pain, fatigue, joint stiffness and an increased risk of cardiovascular issues. Physical activity (PA) has been proven to help reduce the severity of these symptoms and the risk of cardiovascular disease [1]. However, recent literature has shown that people with rheumatoid arthritis do not meet PA guidelines [2]. The systematic review aims to determine the factors which affect the completion rates of adults with $\mathrm{RA}$ in PA interventions.

Objectives: 1) Review the effect of the frequency, intensity, time and type of exercise (FITT principle) on participation rates. 2) Review the reasons for dropping out of an intervention and consider how this can be avoided in planning future interventions. 3) Examine the effect of behaviour change techniques used on completion rates.4) Explore the effect of adverse outcomes on completion rates.

Methods: A systematic review of the literature was carried out in February 2018. Inclusion criteria were: detailed intervention information, completion rates reported, published between 1998-2018 and published in English. Included papers were assessed using the Cochrane risk of bias tool by two assessors. The relevant data was then extracted, compared and conclusions were drawn.

Results: Nine studies with varying levels of quality were included in this review. Reasons for not completing an intervention could be divided into modifiable and non-modifiable factors; modifiable factors include the FITT principle, the behaviour change component and controlling for adverse outcomes. Non-modifiable factors included the environment, illness/flare-up and accidents. The results found that when people with RA had an individualised PA program that started at a low-moderate intensity they had higher participation rates than those who followed a generalised program, with no behaviour change component. Altering the intervention in response to patient's pain levels improved completion rates of the intervention.

Conclusion: When designing PA programs for people with RA, the EULAR PA guidelines for people who have inflammatory arthritis [3] should be followed. However, it should be noted that engagement and participation in PA interventions is increased when the intervention is of low impact PA and starts at a low-moderate intensity. Individualising the activity to the person and applying behaviour change techniques have also been found to improve participation.

\section{REFERENCES :}

[1] Kerschan-Schindl, K. and MacHold, K. (2011) 'Rehabilitation von Patienten mit rheumatoider Arthritis', Physikalische Medizin Rehabilitationsmedizin Kurortmedizin, 21(6), pp. 297-310. doi: 10.4061/2011/681640.

[2] Larkin, L. and Kennedy, N. (2014) 'Correlates of Physical Activity in Adults with Rheumatoid Arthritis: A Systematic Review', Journal of Physical Activity and Health, 11(6), pp. 1248-1261. Doi: 10.1123/jpah.2012-0194.

[3] Rausch Osthoff, A. K. et al. (2018) '2018 EULAR recommendations for physical activity in people with inflammatory arthritis and osteoarthritis', Annals of the Rheumatic Diseases, 77(9), pp. 1251-1260. Doi: 10.1136/ annrheumdis-2018-213585.

Disclosure of Interests: None declared

DOI: 10.1136/annrheumdis-2019-eular.2811

\section{FRI0716-HPR FACTORS WHICH IMPACT COMPLETION AND NON- COMPLETION OF PHYSICAL ACTIVITY INTERVENTIONS FOR PEOPLE WITH RHEUMATOID ARTHRITIS: A SYSTEMATIC REVIEW}

Niamh Reynolds, Louise Larkin. University of Limerick, Limerick, Ireland

Background: Rheumatoid arthritis (RA) is a systemic inflammatory condition which results in pain, fatigue, joint stiffness and an increased risk of cardiovascular issues. Physical activity (PA) has been proven to help reduce the severity of these symptoms and the risk of cardiovascular disease [1]. However, recent literature has shown that people with rheumatoid arthritis do not meet PA guidelines [2]. The systematic review aims to determine the factors which affect the completion rates of adults with $R A$ in PA interventions.

Objectives: 1) Review the effect of the frequency, intensity, time and type of exercise (FITT principle) on participation rates. 2) Review the 
reasons for dropping out of an intervention and consider how this can be avoided in planning future interventions. 3) Examine the effect of behaviour change techniques used on completion rates.4) Explore the effect of adverse outcomes on completion rates.

Methods: A systematic review of the literature was carried out in February 2018. Inclusion criteria were: detailed intervention information, completion rates reported, published between 1998-2018 and published in English. Included papers were assessed using the Cochrane risk of bias tool by two assessors. The relevant data was then extracted, compared and conclusions were drawn.

Results: Nine studies with varying levels of quality were included in this review. Reasons for not completing an intervention could be divided into modifiable and non-modifiable factors; modifiable factors include the FITT principle, the behaviour change component and controlling for adverse outcomes. Non-modifiable factors included the environment, illness/flare-up and accidents. The results found that when people with RA had an individualised PA program that started at a low-moderate intensity they had higher participation rates than those who followed a generalised program, with no behaviour change component. Altering the intervention in response to patient's pain levels improved completion rates of the intervention.

Conclusion: When designing PA programs for people with RA, the EULAR PA guidelines for people who have inflammatory arthritis [3] should be followed. However, it should be noted that engagement and participation in PA interventions is increased when the intervention is of low impact PA and starts at a low-moderate intensity. Individualising the activity to the person and applying behaviour change techniques have also been found to improve participation.

\section{REFERENCES :}

[1] Kerschan-Schindl, K. and MacHold, K. (2011) 'Rehabilitation von Patienten mit rheumatoider Arthritis', Physikalische Medizin Rehabilitationsmedizin Kurortmedizin, 21(6), pp. 297-310. Doi: 10.4061/2011/681640.

[2] Larkin, L. and Kennedy, N. (2014) 'Correlates of Physical Activity in Adults with Rheumatoid Arthritis: A Systematic Review', Journal of Physical Activity and Health, 11(6), pp. 1248-1261. Doi: 10.1123/jpah.2012-0194.

[3] Rausch Osthoff, A. K. et al. (2018) '2018 EULAR recommendations for physical activity in people with inflammatory arthritis and osteoarthritis', Annals of the Rheumatic Diseases, 77(9), pp. 1251-1260. Doi: 10.1136/ annrheumdis-2018-213585.

Disclosure of Interests: None declared

DOI: 10.1136/annrheumdis-2019-eular.4181

\section{FRI0717-HPR A COMPARISON OF THE EFFECTIVENESS OF CORE STABILIZATION EXERCISE AND COMBINED EXERCISE ON PAIN, FATIGUE, SLEEP PROBLEM AND HEALTH STATUS IN WOMEN WITH FIBROMYALGIA}

Oguzhan Mete, Seyda Toprak Celenay, Bahar Anaforoglu Kulunkoglu. Department of Physiotherapy and Rehabilitation, Health Sciences Faculty, Ankara Yildirim Beyazit University, Ankara, Turkey

Background: Fibromyalgia (FM) is a syndrome characterized mainly by chronic widespread pain, fatigue, sleep disorders and decrease in health status. Exercise, one of the non-pharmacological approach, has favorable effects on clinic findings in FM, but studies investigating which types of the exercise are more effective in FM are limited.

Objectives: This study aimed to compare the effectiveness of core stabilization exercise (CSE) and combined exercise (CE) on pain, fatigue, sleep problem and health status in women with FM.

Methods: A total of 34 women with FM were included, allocated into the CSE (n:18, age: $43.05 \pm 9.23$ years, body mass index (BMI): $27.25 \pm 5.23$ $\mathrm{kg} / \mathrm{m}^{2}$ ) and the CE ( $\mathrm{n}: 16$, age: $38.43 \pm 9.55$ years, BMI: $25.62 \pm 3.68 \mathrm{~kg} / \mathrm{m}^{2}$ ) groups. Both the CSE and the CE programs were carried out 2 days a week for 6 weeks under the supervision of a physiotherapist. Pain, fatigue and sleep problems with Visual Analog Scale and health status with Fibromyalgia Impact Questionnaire were evaluated at baseline and after 6-weeks program.

Results: Physical characteristics of the groups were similar $\left(p_{\text {age }}=0.162\right.$, $\left.p_{b m i}=0.313\right)$. After the program, it was found that pain $(p=0.001 ; p=0.014)$, fatigue $(p=0,002 ; p=0.011)$, and sleep problem $(p=0.007 ; p=0.039)$ decreased, health status $(p=0.001 ; p=0.001)$ improved in both the CE and the CSE groups, respectively. Moreover, sleep problem decreased in the CE group in comparison to the CSE group $(p=0.038)$; but pain $(p=0.240)$, fatigue $(p=0.178)$, and health status $(p=0.098)$ did not differ between groups.
Conclusion: In this study, it was observed that both the CSE and the CE programs were effective in decreasing pain, fatigue, sleep problem and improving health status of women with FM. In addition, the study suggested that the CE was superior in decreasing sleep problem in comparison to the CSE in women with FM. In clinics, both the CSE and the CE programs may be preferred to improve the symptoms of $\mathrm{FM}$; however, the CE should be taken into account for the sleep problems in FM.

\section{REFERENCES:}

[1] Busch, A. J., Webber, S. C., Brachaniec, M., Bidonde, J., Dal Bello-Haas, V., Danyliw, A. D.,. .. \& Schachter, C. L. (2011). Exercise therapy for fibro myalgia. Current pain and headache reports, 15(5), 358

[2] Sosa-Reina, M. D., Nunez-Nagy, S., Gallego-Izquierdo, T., Pecos-Martín, D., Monserrat, J., \& Álvarez-Mon, M. (2017). Effectiveness of therapeutic exercise in fibromyalgia syndrome: a systematic review and meta-analysis of randomized clinical trials. BioMed research international, 2017.

Disclosure of Interests: None declared

DOI: 10.1136/annrheumdis-2019-eular.2867

\section{FRI0718-HPR THE EFFECT OF THE BIOPSYCHOSOCIAL EXERCISE PROGRAM ON PAIN COPING SKILL AND FATIGUE IN RHEUMATIC DISEASES}

Aykut Özçadırcı $^{1}$, Gamze Arın ${ }^{1}$, Yasemin Özel Aslıyüce ${ }^{1}$, Fatma

Birgül Kumbaroğlu ${ }^{1}$, Nur Banu Karaca ${ }^{1}$, Aybüke Seven ${ }^{1}$, Sedat Kiraz ${ }^{2}$,

Ali Akdoğan², Edibe Ünal'. ${ }^{1}$ Hacettepe University Faculty of Physical Therapy and

Rehabilitation, Ankara, Turkey; ${ }^{2}$ Hacettepe Universiy Faculty of Medicine,

Department of Rheumatology, Ankara, Turkey

Background: Although the trend towards biopsychosocial approaches is increasing today, studies on psychosocial effects of exercise are limited in the literature. There is a need for framed exercise programs to assess the clinical effectiveness of biopsychosocial approaches. The reason why biopsychosocial programs are important may be due to multidimensional features of symptoms such as pain, fatigue.

Objectives: The purpose of this study is to investigate the effectiveness of the biopsychosocial exercise program on pain coping skill and fatigue in rheumatic patients.

Methods: Ninety-one patients with the rheumatic disease were included in this study. The patients were divided into two groups based on a prospective cohort (BETY group, $\mathrm{n}=56$; and control group, $\mathrm{n}=35$ ). BETY is a biopsychosocial exercise approach (1). It was performed in a period of one hour, 3 times a week for 12 weeks and included clinical pilates exercises, dance therapy-authentic movement and pain management information. The control group did not take any exercise treatment. The BETY-Biopsychosocial Questionnaire (BETY-BQ) was used to evaluate the pain coping skill and fatigue as well as assessing whole biopsychosocial status of individuals (2). The answers were given to the 5 th question (I don't know how to control my pain.) and the 11th question (I feel tired.) of the BETY-BQ were recorded as a 5-point Likert at ranging from 'yes, always' to 'no, never. Also, the total score of BETY-BQ was recorded. Demographic data were given as mean \pm standard deviation $(X \pm S D)$, and answers given to the questionnaire were expressed in frequency tables.

Results: The mean ages of BETY group and control group were $49.63 \pm$ 11 and $39.74 \pm 10$ years and body mass indexes were $26.93 \pm 3 \mathrm{~kg} /$ $\mathrm{m} 2$ and $26,54 \pm 4 \mathrm{~kg} / \mathrm{m} 2$, respectively. The frequency of answers to the 5th and 11th question and the total score of the BETY-BQ on the first assessment (pre-treatment) and the second assessment (post-treatment) were shown in Table 1 .

FRI0718HPR Table 1. Comparison of assessment results

\begin{tabular}{lcccccc}
\hline & \multicolumn{2}{c}{ BETY exercise group } & \multicolumn{3}{c}{ Control Group } \\
\hline & $\begin{array}{c}\text { Pre- } \\
\text { treatment }\end{array}$ & $\begin{array}{c}\text { Post- } \\
\text { treatment }\end{array}$ & $\mathbf{p}$ & $\begin{array}{c}\text { Pre- } \\
\text { treatment }\end{array}$ & $\begin{array}{c}\text { Post- } \\
\text { treatment }\end{array}$ & $\mathbf{p}$ \\
\hline $\begin{array}{l}\text { BETY-BQ (0- } \\
\text { 120) }\end{array}$ & $54.60 \pm 27$ & $38.55 \pm 25$ & $<0,001$ & $56.51 \pm 24$ & $53.63 \pm 28$ & 0.221 \\
5th question & & & & & & \\
$\begin{array}{l}\text { Yes always } \\
\text { (\%) }\end{array}$ & 24.1 & 7.4 & $<0,001$ & 28.6 & 28.6 & 0.734 \\
Yes often (\%) & 7.4 & 3.7 & & 20 & 14.3 & \\
Yes & 25.9 & 22.2 & & 8.6 & 17.1 & \\
sometimes & & & & & & \\
(\%) & & & & & & \\
Yes rarely (\%) & 25.9 & 20.4 & & 17.1 & 8.6 & \\
No never (\%) & 16.7 & 46.3 & & 25.7 & 31.4 &
\end{tabular}

